\title{
A DESTRUIÇÃO DA AURA E O ENTKUNSTUNG DA ARTE COMO RESULTADO DA REPRODUTIBILIDADE TÉCNICA
}

Emanuelle Beserra de Oliveira

\begin{abstract}
RESUMO
A rapidez com que a técnica avançou na era pós-industrial acelerou o desenvolvimento da reprodutibilidade técnica que acabou por transformar o que se entendia por obra de arte. Com a reprodução, a arte perde o seu valor de culto e se aproxima do espectador que tem a possibilidade de levar para si uma cópia do objeto desejado. Característico dessa fase pós-aurática da arte marcado pela lógica do capital é o conceito adorniano de Entkunstung.
\end{abstract}

Palavras-Chave: Arte. Técnica. Reprodutibilidade. Entkunstung. Aura.

\section{THE DESTRUCTION OF THE AURA AND ENTKUNSTUNG OF ART AS RESULT OF THE TECHNICAL REPRODUCTION}

\begin{abstract}
The quickness on which the technique advanced in the post-industrial era accelerated the development of technical reproduction that ended up transforming what it was understood by art. With the reproduction, art loses its value of worship and approachs the viewer, that has the possibility of taking a copy of the desired object. Peculiar to this post-auratic phase of art marked by the logic of capital is the adornian concept of Entkunstung.
\end{abstract}

Keywords: Art. Technique. Reproducibility. Entkunstung. Aura. 


\section{Introdução}

Os tempos modernos estabelecem a autonomia da razão, trazendo a tona uma nova visão de realidade social, cultural e econômica. A razão se torna fator indispensável ao entendimento do novo mundo que se anunciava. A interface utilitarista deste projeto moderno se consolida na revolução industrial marcando também a produção artística da passagem do século XIX ao XX, e a submetendo ao molde industrial. Não era suficiente dominar uma arte, mas, sim, dominar uma técnica.

A técnica por sua vez acarretou duas perdas, por um lado temos um fenômeno denominado de Entkunstung da arte que se caracteriza pela perda do caráter artístico de uma obra de arte, denunciado por Theodor Adorno e por outro a destruição da aura evidenciada por Walter Benjamin. Mas o que esses dois fenômenos tem em comum para analisar o fazer artístico no período atual? Sem dúvida a técnica é o sujeito principal na análise dos fenômenos elucidados acima e que concilia o pensamento dos dois autores no que se refere a não renegar o seu uso, mas sim saber utilizá-la com responsabilidade artística.

Adorno analisa o distanciamento contemplativo que separava a arte da realidade. Esse fenômeno torna a arte suscetível a intervenções. O próprio mercado tenta interferir no processo de produção, tornando a obra mais acessível a todos, sem se preocupar com a exploração e a violência que é impetrada contra o indivíduo. Ou seja, não cabe somente ao artista despejar seu conteúdo subjetivo, sua sensibilidade. Por outro lado, essa exponibilidade da arte colabora diretamente, em Benjamin, na democratização da arte. O acesso ao conteúdo artístico permite a massa sentir-se inserida na obra exposta.

\section{Entkunstung da Arte (Desartificação da Arte)}

A arte perdeu seu sentido legado pela tradição, na medida em que a sociedade foi se "desumanizando" pelos processos de automatização. O tão sonhado ideal do Aufklärung que visava devolver a autonomia para o indivíduo the condicionou a um outro domínio, o da racionalidade técnica: "O programa do 
esclarecimento era o desencantamento do mundo"1, mas esse projeto pagou um preço alto, uma vez livre do medo do mito, o homem passou a se submeter ao poder da razão instrumental ${ }^{2}$. A arte, por sua vez, não fica isenta dessa submissão, pois passa a ser explorada por fins ideológicos e comerciais, entrando num processo que Adorno denominou de Entkunstung ${ }^{3}$ da arte, fenômeno que se caracteriza pela perda do caráter artístico de uma obra de arte. Apesar de ser um conceito desenvolvido na Teoria Estética (1970), Adorno sinalizou uma primeira consideração sobre o termo, ainda sob o conceito de uma arte desartizada (Entkunstet), em seu texto Moda intemporal - sobre o jazz que foi publicado em sua obra Prismas ${ }^{4}$ (1969).

Os jovens ainda não são dominados pela vida econômica e por seu correlato mental, "o princípio de realidade". Seus impulsos estéticos não são facilmente apagados pela submissão, mas apenas desviados. $O$ jazz é o meio preferido desse desvio. (ADORNO, 1998, 129)

Indícios desse conceito não se fazem presentes de forma clara em seu texto sobre a indústria cultural, na Dialética do Esclarecimento (1944), mas não podemos deixar de salientar que mesmo de forma implícita aparece no referido texto, na medida em que trata de alguns elementos, tais como: conteúdo de verdade, nãoidentidade, caráter enigmático que evidenciam a "desartificação". Tais indícios se revelam na discussão da paixão pelo palpável e do adestramento feito pela cultura de massa.

A arte precisa de um certo distanciamento entre o objeto e o sujeito que a contempla para haver um real entendimento acerca da obra, obtendo dessa forma a verdade e o conhecimento que o objeto estético possui e deve transmitir. Entretanto,

ADORNO; HORKHEIMER, 1985, p. 17.

2 Termo utilizado por Marx Horkheimer no contexto de sua teoria crítica para designar o estado em que os processos racionais são totalmente operacionalizados, à esta razão pode se opor a razão crítica.

3 Adorno empregou esse termo pela primeira vez em seu livro Prismas (1955), denunciando o fenômeno do jazz.

4 Ele fornece às massas de jovens que a cada ano aderem a essa moda intemporal - muito provavelmente para esquecê-la após alguns anos - um compromisso intermediário entre a sublimação estética e a adaptação social. O elemento "irrealista", imaginativo e não-pragmático é admitido na medida em que se assemelha cada vez mais, no seu próprio caráter, ao movimento real, reproduzindo e obedecendo a seus mandamentos. A arte é desartizada [entkunstet]: ela mesma se transforma em peça daquela adaptação que é contrária a seu próprio princípio. (ADORNO, 1998, p. 129)

Mestre em Filosofia (UECE). Pesquisadora do grupo "Walter Benjamin e a Filosofia Contemporânea" (CNPQ). Brasileira, residente em Fortaleza - CE, E-mail: manubazik@hotmail.com 
o que acontece na atualidade é uma total aproximação do objeto estético ao alcance do contemplador, o que deturpa o objetivo real da obra de arte, condicionando os indivíduos a uma paixão pelo palpável. Este conceito constitui o fenômeno, no qual o espectador não se contenta somente em ver o objeto, ele o deseja - e aqui se abre uma categoria muito importante para entender o processo de domínio pela indústria cultural - o possuir. $O$ desejo passa a ser um sentimento que invade a classe dominada. O consumidor projeta na obra a esperança de que, ao possuí-la, esta lhe proporcione algo além de sua verdade ou conhecimento, que seria o verdadeiro objetivo da arte. O espectador força uma aproximação, fazendo a obra ser semelhante a ele ao invés de buscar uma compreensão crítica daquilo que está contemplando. Decerto o espectador acredita na semelhança do objeto consigo e, dessa maneira, esse objeto artístico passa a ser um talismã da identidade. É isso que a indústria cultural faz: manipula de forma falseada essa relação entre a arte e a realidade.

Oferecendo instantes de felicidade e satisfação, a indústria promete um prazer que nunca é alcançado, porque a máquina que move o consumo gira muito rapidamente, pois "ao mesmo tempo que já determina o consumo, ela descarta o que ainda não foi experimentado porque é um risco" ADORNO, HORKHEIMER, 1985, 111). Da mesma forma que promete o prazer com a posse de algo, ela o nega ao indivíduo, criando um ciclo vicioso que auxilia na destruição da produção artística, enquanto evidencia a necessidade da substituição do objeto de arte. Pois, "A indústria cultural não cessa de lograr seus consumidores quanto àquilo que está continuamente a lhes prometer. A promissória sobre o prazer, emitida pelo enredo e pela encenação, é prorrogada indefinidamente: maldosamente" (Idem, 115). A eterna promessa significa o distanciamento da coisa mesma, deixa o espectador se contentar com o que é exposto numa vitrine. Adorno atenta que este é o segredo da sublimação estética: "apresentar a satisfação como uma promessa rompida. A indústria cultural não sublima, mas reprime".(Idem, 115)

E a partir do momento em que é reprimido o desejo, o indivíduo se sente desamparado dentro da sociedade, a obra traz a esperança de que, ao possuí-la, esta lhe proporcionará importância e prestígio àquele que a possui. Existe hoje uma "necessidade imanente ao sistema de não soltar o consumidor, de não lhe dar em 
nenhum momento o pressentimento da possibilidade de resistência"(Idem, 117). E sem resistência a sociedade não é capaz de gerar indivíduos conscientes, capazes de produzir arte autêntica. Somente espectadores que forçam uma aproximação, fazendo a obra ser semelhante e deixando de lado o conhecimento real daquilo que está contemplando. De certo modo, o consumidor-contemplador acredita nessa semelhança consigo mesmo. E será essa semelhança que o fará entrar num estado de alienação inconsciente.

Para Adorno com a dessacralização da arte e sua exponibilidade, a era industrial reduziu a arte a nada mais que mercadoria, mais um produto de consumo lançado no mercado. No mundo atual, quase tudo pode ser considerado arte, não se leva mais em consideração o porquê de se fazer arte; esta é produzida com intenções, quase que exclusivas em atender à indústria da cultura. Incapaz de desenvolver um potencial crítico no espectador, ela chega como objeto de desejo e não de conhecimento, ajustada e preparada para atender aos interesses da camada dominante. Adorno atenta para esse fato da arte "desartizada" em todas as suas expressões, seja ela na música, no cinema ou na literatura, mostrando que

nada deve ser o que é em si, tudo deve ser ajustado, deve ter os vestígios de uma preparação que, pela aproximação a algo já conhecido, torna tudo mais compreensível, confirmando que tudo está à disposição do ouvinte, sem idealizá-lo (ADORNO, 1998, 129).

Para Adorno a arte é conhecimento, mas não de objetos; só compreende uma obra de arte quem a compreende como complexão da verdade. Compreender ${ }^{5}$ obras de arte significa perceber o momento de sua "logicidade e do seu contrário, também das suas falhas e do que significam"(ADORNO, 2003, 293). A arte visa à verdade, ela é conhecimento mediante a sua relação com a verdade.

Mas como obter essa complexão da verdade ou de um saber de uma obra que se encontra presa nas amarras da indústria cultural? A indústria cultural acaba

5 Compreender é também perceber o seu conteúdo como um elemento espiritual, através da plena experiência da obra de arte. Isso diz respeito tanto à sua relação com o tema, com a aparição e a intenção, como à sua própria verdade ou falsidade, segundo a lógica específica das obras de arte que ensina a distinguir nelas o verdadeiro e o falso. As obras de arte só são compreendidas quando a sua experiência estética, alcança a alternativa do verdadeiro e do inverdadeiro ou como seu estado anterior a alternativa do justo e do errado. A crítica não se apresenta de fora mas é-lhe imanente. Conceber uma obra de arte como complexão de verdade, põe-na em relação com a sua inverdade, pois não existe obra alguma que não participe no inverdadeiro fora dela, no da idade do mundo. (ADORNO, 2003, p. 381-382)

Mestre em Filosofia (UECE). Pesquisadora do grupo "Walter Benjamin e a Filosofia Contemporânea" (CNPQ). Brasileira, residente em Fortaleza - CE, E-mail: manubazik@hotmail.com 
tornando a arte uma mercadoria, incluindo-a entre os bens de consumo e essa inclusão se dá como uma forma de reduzir a distância entre a arte e a vida do indivíduo, levando ao aniquilamento do conceito tradicional de obra de arte. Muitos comentadores afirmam ser Adorno um elitista por ele defender a necessidade de um distanciamento entre a arte e o indivíduo, porém, o que Adorno tenta fazer é possibilitar a cada um o acesso à boa arte, capaz de induzir a questionamentos e potencializar a ação crítica.

Mas que arte seria essa? Apesar de todo o pensamento pessimista deve-se atentar para um texto de 1966, Notas sobre o filme de Theodor Adorno onde ele afirma que "o meio técnico par excellence é profundamente aparentado com a beleza natural'(ADORNO, 1986, 102). A arte é livre e não se limita a uma determinada condição. É a expressão mais verdadeira do homem que tem o poder de causar bem estar (aisthesis) através do valor que representa: a beleza, o belo. Este valor de verdade que a arte possui é o que fará a sintonia do indivíduo com a obra. Se a arte pretende uma mímesis da natureza, Adorno aponta que essa imitação seria a do belo natural. As forças produtivas, por sua vez, acabaram por substituir o belo natural pelo belo artístico. A mímesis do belo natural ${ }^{6}$ não seria dominação, mas o único lugar da liberdade possível.

Para Adorno, a intenção não é um ingrediente essencial da obra de arte. A intenção jamais deve aparecer numa arte verdadeira. A obra de arte só é considerada arte quando vira ruína, pois somente naquele momento ela se liberta das vicissitudes históricas. Quanto a esse ponto coincidem Adorno e Benjamin. A arte procura imitar uma expressão, que não incluiria a intencionalidade. Esta é apenas o seu veículo. Quanto mais perfeita uma obra de arte, mais as intenções dela se ausentam. A natureza, indiretamente o conteúdo de verdade da arte, elabora imediatamente o seu contrário. Se a linguagem da natureza é muda, a arte aspira a fazer falar o silêncio, exposta ao insucesso pela contradição insuperável entre esta ideia, que impõe o esforço desesperado, e aquela, a que se aplica o esforço, de um

${ }^{6}$ O belo, na natureza, é o que aparece como algo mais do que o que existe literalmente no seu lugar. Sem receptividade, não existiria uma tal expressão objetiva, mas ela não se reduz ao sujeito; o belo natural aponta para o primado do objeto na experiência subjetiva. Ele é percebido ao mesmo tempo como algo de compulsivamente obrigatório e como incompreensível, que espera interrogativamente a sua resolução [...] Sob este seu aspecto, a arte é, em vez de imitação da natureza, uma imitação do belo natural. (ADORNO, 2003, p. 87)

Mestre em Filosofia (UECE). Pesquisadora do grupo "Walter Benjamin e a Filosofia Contemporânea" (CNPQ). Brasileira, residente em Fortaleza - CE, E-mail: manubazik@hotmail.com 
não intencional puro e simples. Portanto, no mundo da eterna cópia, a mímesis, para ser verdadeira, deve retornar ao belo natural, pois inserido na sociedade totalmente administrada, a mímesis recai numa imitação pela imitação, sem conteúdo de verdade, ou seja, recai numa falsa mímesis.

\section{Destruição da Aura}

A reprodutibilidade técnica da arte, que Benjamin mostra em sua obra, não é nada mais e nada menos que a interferência do processo industrial na produção artística. Novas técnicas são desenvolvidas, abrindo espaço para novos processos de produção e reprodução artísticas. Benjamin mostra em seu texto, $A$ obra de arte na época de sua reprodutibilidade técnica (1935/36) exemplos da evolução da reprodução, tais como: escrita, xilogravura, litografia, fotografia que acabam por divulgar e fazer circular de forma mais acessível as obras de arte. A massa passa a ter acesso ao que antes era mais restrito a um grupo de privilegiados.

Para Benjamin, a obra de arte sempre foi reprodutível, tudo podia ser imitado, desde um simples gesto a uma obra de arte com a finalidade de sua difusão. Entretanto o que se observa com a reprodução técnica é que algo novo aconteceu, aparelho e homem mantem uma relação nova onde estão ligados desde o seu processo de produção até o de reprodução para sua difusão. As transformações e evoluções da humanidade aceleraram e caminharam junto com o processo de reprodução, de novas criações que se renovam diariamente e que reivindicavam uma aceleração no processo artístico.

A preocupação que se deve ter com essa entrada da arte no processo industrial é se a mesma ocasiona a perda de autenticidade, ou seja, do caráter original da obra. Para Benjamin mesmo a reprodução mais perfeita, deixava ausente o aqui e agora (hic et nunc) da obra de arte, ou seja, sua existência única. O conteúdo de autenticidade da obra é constituído pelo aqui e agora do original. Será esse conteúdo que identificará o objeto como sendo sempre igual e idêntico a si mesmo. A arte, tal como a conhecíamos, era única, possuía uma unidade, um hic et nunc. Mesmo com a existência da reprodução manual, era escassa a difusão de cópias devido ao trabalho difícil e demorado que poucos sabiam fazer. A obra de 
arte mantinha, através de sua aura, seu brilho e sua durabilidade que a consagravam como testemunho histórico.

Com o advento da fotografia, o valor de culto recua diante da grande difusão das obras e do alcance sobre o original. O olhar do espectador modifica e quer avançar mais e mais, reconfigurando sua sensibilidade como observador. A reprodução técnica tem autonomia sobre o objeto original, pois através da técnica é possível chegar mais além e atingir níveis de observação que a reprodução manual nunca fora capaz. Ela pode "aproximar do receptor a obra, seja sob a forma da fotografia, seja do disco. A catedral abandona seu lugar para instalar-se no estúdio de um amador; o coro, executado numa sala ao ar livre, pode ser ouvido num quarto" (BENJAMIN, 2012a, 182). Mas mesmo com o avanço da reprodução técnica sobre a reprodução manual que acaba por deixar intacta a continuidade da obra de arte, o aqui e agora continua desvalorizado. Afeta sua autenticidade, pois viola a unidade que o objeto resguardava, perdendo a unicidade, a arte perde também sua durabilidade.

Nessa linha de pensamento Benjamin desenvolve sua análise sobre a aura, ou seja, o que retém a unidade da obra, mostrando que "o que desaparece na época da reprodutibilidade técnica da obra de arte é sua aura. Esse processo é sintomático; seu significado vai muito além da esfera da arte"(BENJAMIN, 2012 a, 182). A aura em Benjamin pode ser compreendida como "uma teia singular, composta de elementos espaciais e temporais: a aparição única de uma coisa distante, por mais perto que ela esteja"(BENJAMIN, 2012 a 184). A reprodução atinge a aura do objeto reproduzido.

Se a obra de arte exigia o distanciamento para sua contemplação e compreensão, essa relação de distância do espectador para com o objeto é rompida pela proximidade que a fotografia ${ }^{7}$ inaugura com suas imagens cada vez mais nítidas e expostas na cara do contemplador, revelando o inconsciente ótico assim

\footnotetext{
7 A fotografia torna-a acessível, através dos seus recursos auxiliares: câmara lenta, ampliação. Só a fotografia revela esse inconsciente ótico, como só a psicanálise revela o inconsciente pulsional. Características estruturais, tecidos celulares, com os quais operam a técnica e a medicina, tudo isso tem uma afinidade mais originária com a câmara do que a paisagem impregnada de estados afetivos, ou o retrato que exprime a alma do seu modelo. (BENJAMIN, 2012b. p. 100-101).
} 
como a psicanálise revelou o inconsciente pulsional, devido à experiência da imagem com as novas técnicas para sua modificação.

O declínio atual da aura pode ser exemplificado com o que Adorno posteriormente denominou paixão pelo palpável (Leidenschaft zum Antasten), pois devido à grande difusão e intensidade dos movimentos de massa, esta tem a preocupação de fazer as coisas ficarem cada vez mais próximas, tornando difícil resistir à necessidade de possuir o objeto, a uma crescente vontade de tê-lo o mais perto possível. O consumidor projeta no objeto a esperança de que, ao possuir o objeto de arte, este lhe proporcione algo além de sua verdade ou conhecimento, fazendo a obra ser semelhante a ele ao invés de buscar uma compreensão crítica daquilo que está contemplando.

Contudo, essa perda da aura não é vista de forma totalmente negativa por Benjamin que acaba criando novos horizontes de relacionamentos com o mundo de imagens. Com a perda da aura a obra torna-se independente do contexto histórico, no qual está inserida e das tradições que carrega, a obra adquire significação no hoje, no aqui e agora. As obras de arte se libertam, passam a ser expostas através da reprodução técnica, o que permite um maior acesso a todos, tornando-se apropriação do coletivo.

Percebe-se que na própria reprodutibilidade, substitui-se a existência única de uma obra por uma existência em larga escala. Permitindo a obra vir ao encontro do espectador, ao ser atualizado o objeto de arte. $O$ valor de culto (Kultwert) é substituído pelo valor de exposição (Ausstellungwert). Para Benjamin a reprodutibilidade técnica da obra de arte emancipa-a, pela primeira vez na história, de sua existência parasitária no ritual, onde a "obra de arte reproduzida é cada vez mais a reprodução de uma obra de arte criada para ser reproduzida"(BENJAMIN, 2012 a, 186). Portanto, na medida em que as obras se emancipam do uso cultual, se inclinam para seu lado expositivo.

A exponibilidade de uma obra de arte cresceu em uma escala tão descomunal, com os vários métodos de sua reprodutibilidade técnica, que a mudança de ênfase de um polo para outro corresponde a uma mudança qualitativa comparável à que ocorreu na pré-história (BENJAMIN, 2012 a, 187)

Mestre em Filosofia (UECE). Pesquisadora do grupo "Walter Benjamin e a Filosofia Contemporânea" (CNPQ). Brasileira, residente em Fortaleza - CE, E-mail: manubazik@hotmail.com 
Um dos maiores exemplos de objeto com valor de exposição são os filmes ${ }^{8}$. 0 cinema provocou uma revolução maior que a fotografia, por ser o produto de uma coletividade que apresenta um novo espanto e magia. Ao falar de cinema Benjamin nos diz que a reprodutibilidade de um filme não é como a de um livro ou um quadro, a reprodutibilidade técnica no cinema se fundamenta na técnica de sua produção, que não só permite a difusão em massa como a torna obrigatória, visto que produzir um filme tem um custo bastante elevado. Sua difusão é necessária para arcar com esses custos, já que o consumidor, em sua época, não pode pagar por um filme da mesma forma que ele paga por um livro ou quadro. Neste caso o cinema não tem mais como resguardar em suas produções 0 valor de culto. $O$ filme deve ser exposto, rompendo com o ritual e se fundando numa práxis política.

O cinema, como arte perfectível, resulta na hora da montagem, onde o aparelho impregna tão intimamente o real que o filme aparece como realidade pura. Apesar de toda impregnação da técnica, onde uma câmera captura a imagem e outras a montam, percebemos o equilíbrio entre homem e aparelho, que vem a ser uma das funções sociais que cabe ao cinema, vista numa visão benjaminiana. As imagens na grande tela nos provocam efeitos na percepção de nossos atos e gestos diários. E é a perfeição da montagem que nos condicionará a imergir e emergir nos guiando para experiências em nosso inconsciente. Visto que "os filmes grotescos dos Estados Unidos, e os filmes de Disney provocam uma explosão terapêutica do inconsciente"(BENJAMIN, 2012 a, 205), essa explosão se configura no choque (Chockerlebnis), sintoma da era pós-industrial.

Para Benjamin, o cinema "serve para exercitar o homem nas novas percepções e reações exigidas por um aparelho técnico, cujo papel cresce cada vez mais em sua vida cotidiana"(BENJAMIN, 2012 a, 188). Porém Benjamin, por possuir uma filosofia de alerta, do que se apresenta como agente modificador das relações humanas, nos deixa atentos para a distração e o entretenimento negativo que 0 cinema possa nos proporcionar, formando hábitos automatizados, pois é visto que a arte tem a capacidade de mobilizar a massa por seu alto poder de distração. Para Benjamin, o cinema faz a recepção através da distração: "a massa procuraria a distração, enquanto que o amante da arte se aproximaria desta com recolhimento.

8 Para Benjamin o filme é uma forma cujo caráter artístico é pela primeira vez determinado por sua reprodutibilidade. O filme é, pois, a mais perfectível das obras de arte.

Mestre em Filosofia (UECE). Pesquisadora do grupo "Walter Benjamin e a Filosofia Contemporânea" (CNPQ). Brasileira, residente em Fortaleza - CE, E-mail: manubazik@hotmail.com 
Para as massas, a obra de arte seria objeto de diversão e para o conhecedor, objeto de devoção" (BENJAMIN, 2012 a, 188) E será através do efeito de choque que o cinema causa, que este vem ao encontro dessa forma de recepção.

A questão da arte, para Benjamin, deve também ser entendida como uma questão política que sofre modificações ao longo do tempo, sejam elas mais brandas ou drásticas. $\mathrm{O}$ modo como as pessoas percebem a realidade também se modifica ao passar do tempo e a mudança da arte também se deve a esse fato. À medida que a sensibilidade e mentalidade humana se desenvolvem, a arte caminha no mesmo rumo, se modifica por conta de sua natureza e de sua história. Diferente de Adorno, Benjamin não se prende somente a denúncia da transformação da arte em mercadoria, perdendo assim seu caráter de arte, percebe-se sim uma tentativa de pensar a possibilidade de utilizá-la como uma ferramenta eficaz na conscientização política. Com este alcance que a arte na era pós-aurática possui e com sua proximidade a massa, é possível esperar que ela tenha uma finalidade no momento histórico no qual as massas são esmagadas pela ditadura do capital.

\section{Considerações Finais}

Fica claro no pensamento dos dois autores que ao analisar o papel da arte na era pós-aurática, esta sofreu grandes transformações. Acompanhando o movimento da humanidade e suas descobertas, a arte não ficou isenta de absorver o que a revolução industrial impulsionou. Por um lado, temos arte como mercadoria que perdeu seu caráter enquanto arte e não desempenha mais seu papel de transmitir conhecimento e estimular a reflexão do indivíduo. Por outro lado, temos a arte democratizada, acessível que fez uso da técnica para reproduzir massivamente e atingir a coletividade.

A existência da arte na contemporaneidade é bastante questionável pelos filósofos da teoria crítica. Mas quem são as pessoas certas a dizerem o que é ou não arte? A arte teve que acompanhar as mudanças da sociedade, da economia, da sensibilidade humana e ela continuará a se reproduzir e a testemunhar a história dos homens ao longo de tempo. A dessacralização cedeu espaço para a exposição, o momento de reclusão para refletir sobre a arte apreciada já não existe, a arte em seus primórdios possuía um caráter inatingível perante seu espectador, entretanto a 
técnica a arrasta para o alcance do espectador. A sociedade do choque não permite mais esse momento de pausa e contemplação, a rapidez com que a vida é levada impede a reflexão, fazendo com que os sons e imagens substituam os próprios pensamentos do indivíduo.

Ao analisar os dois fenômenos apresentados é visível a distinção no qual Theodor Adorno e Walter Benjamin se apoiam para encarar o problema ou estado da arte de sua época. Enquanto Benjamin tenta pensar numa obra de arte enquanto um momento de se educar, com a atitude de resistência, utilizando a técnica a serviço de uma democratização do objeto artístico, fazendo uso da poesia, da literatura, Adorno vê o problema da arte como uma situação aporética que requer um esforço teórico para resgatar o meio técnico par excellence ao fazer o retorno ao belo natural, um retorno a uma arte livre de intenções e que preserve sua autenticidade e transmita seu conteúdo de verdade. 


\section{REFERÊNCIAS}

ADORNO, Theodor W. Indústria cultural: o esclarecimento como mistificação das massas. In: Dialética do Esclarecimento. Tradução de Guido A. de Almeida. Rio de Janeiro: Jorge Zahar Editor, 1985.

1998.

. Prismas: crítica cultural e sociedade. São Paulo: Ática, Portugal: Edições 70, 2003.

Teoria Estética. Tradução de Artur Morão. Lisboa -

Notas sobre o filme [1966]. In: Cohn, Gabriel (org.). Theodor W. Adorno. São Paulo: Ática, 1986 (coleção Grandes Cientistas Sociais), pp.100-107.

BENJAMIN, W. A obra de arte na era de sua reprodutibilidade técnica. In: Magia, arte e técnica: ensaios sobre a literatura e história da cultura. São Paulo: Brasiliense, 2012a - (Obras Escolhidas, v.1).

A pequena história da fotografia. In: Magia, arte e técnica: ensaios sobre a literatura e história da cultura. São Paulo: Brasiliense, 2012b (Obras Escolhidas, v.1.)

Rouanet. São Paulo: Brasiliense, 1984.

Origem do drama barroco alemão. Trad. br. Sérgio Paulo

$\mathrm{COHN}$, Gabriel. Introdução: Adorno e a teoria crítica da sociedade. In: Cohn, Gabriel (org.). Theodor W. Adorno. São Paulo: Ática, 1986 (coleção Grandes Cientistas Sociais), pp.7-30.

DUARTE, Rodrigo. Teoria crítica da indústria cultural. Belo Horizonte: Editora UFMG, 2003.

KOTHE, Flávio René. Benjamin \& Adorno: confrontos. São Paulo: Ática, 1978.

PENNA, Tiago. O cinema e a percepção sensível. In: Cadernos Walter Benjamin, Volume 2, pp. 36-53, 2009. Revista Eletrônica - www.gewebe.com.br. 